\title{
Extra Pancreatic Necrotic Volume: Can It Prognosticate Acute Necrotising Pancreatitis- A Prospective Study
}

\author{
Rinoy Ram Anandan ${ }^{1}$ Santosh Patil ${ }^{1}$ Rupa Renganathan ${ }^{1} \quad$ Rajesh Kumar Varatharajaperumal ${ }^{1}$ \\ Rajkumar Ramasamy ${ }^{1}$ Venkatesh Kasi Arunachalam ${ }^{1}$
}

${ }^{1}$ Department of Radiology, Kovai Medical Center and Hospital, Coimbatore, India

J Gastrointestinal Abdominal Radiol ISGAR:2020;3(suppl S1):S15-S21

\begin{abstract}
Address for correspondence Venkatesh Kasi Arunachalam, DMRD, DNB, FRCR, Department of Radiology, Kovai Medical Center and Hospital, Avanashi Road, Coimbatore 641014, India (e-mail: drkasivenkatesh@yahoo.co.in).
\end{abstract}

\section{Abstract \\ Keywords \\ - extra pancreatic necrosis \\ - acute necrotising pancreatitis \\ - modified CTSI \\ - organ failure \\ - percutaneous intervention}

Background Acute necrotizing pancreatitis (ANP) is associated with higher mortality and morbidity. We need a method which is accurate in predicting the prognosis, and when applied early in the disease process, can help in closer monitoring and early initiation of treatment for at-risk patients.

Objectives The aim of this prospective study was to assess the extra pancreatic necrosis (EPN) volume in patients with ANP and compare it with outcome variables such as organ failure, death and need for intervention as well as to compare the predictive power of EPN volume with modified CT severity index (CTSI).

Materials and Methods The study had 48 patients with clinical diagnosis of acute pancreatitis, who underwent Contrast enhanced CT (CECT) between 3-6 days of onset. In all these patients, EPN volume (in cubic centimetre) and modified CTSI score were calculated and compared with the patient outcome parameters such as duration of hospital/ICU stay, need for percutaneous/surgical intervention, evidence of infection and organ failure. The results were compared with assess the predictive power of EPN volume.

Statistical analysis The analysis was done in SPSS version 16.0 for windows. Pearson Correlation was used to assess the significant relationship between selected objective variables.

Results EPN volume ( $>/=$ to $360 \mathrm{cc}$ ) had a statistically significant correlation with outcome parameters as well as in predicting overall organ failure. In our study, Modified CTSI had no significant correlation with the above mentioned factors.

Conclusions The volume of EPN calculated between $3^{\text {rd }}$ and $6^{\text {th }}$ day of onset of symptoms showed a significant correlation with the outcome in patients with ANP.

\section{Introduction}

Acute pancreatitis is a complex process in which pancreatic enzyme activation causes local pancreatic damage, resulting in an acute inflammatory response. It has a variable severity in each patient with an unpredictable outcome. About $15 \%$ to $20 \%$ of

DOI https://doi.org/ $10.1055 / \mathrm{s}-0040-1714446$ ISSN 2581-9933. patients will develop a complicated clinical course characterized by organ failure and/or local complications, 10 to $15 \%$ of the patients may culminate in death. ${ }^{1,2}$

Several clinical and radiological scoring systems were developed earlier to assess the severity of acute pancreatitis and to predict the prognosis. In 1985 Balthazar et al. 
developed a CT (computed tomography) based scoring system with 5 grades (A-E) based on the presence of pancreatic and peripancreatic inflammation. ${ }^{3}$

Further development on this scoring was made when extra pancreatic necrosis was added to it and was termed as the CT severity index (CTSI). In 2004, a modified CTSI (MCTSI) was designed to account for several potential limitations of the CTSI. In contrast to the CTSI, the MCTSI incorporates extra pancreatic complications in the assessment. ${ }^{4}$

With development of investigative and treatment options the necessity of an accurate classification also increased. In 2012 a revision of the Atlanta classification of acute pancreatitis was introduced, with a goal to accurately classify the pancreatitis and to remove the confusing terms which was pre-existent, thus aiding accurate management and follow up of those patients. ${ }^{5,6}$

Acute necrotizing pancreatitis is associated with higher mortality (2-39\%) and morbidity(34-95\%) than oedematous pancreatitis. ${ }^{7-10}$ The rationale for assessing the severity of acute pancreatitis is mainly practical: mild pancreatitis responds well to supportive therapy, whereas severe pancreatitis requires intensive monitoring and specific therapies and has a more guarded prognosis.

We need a method which is accurate, easy to use, reproducible with less interobserver variability and easily available for prognostication. It should be relevant that, when applied early in the disease process, the patients who are at risk of developing complications can be closely monitored and empirically treated early.

Since 1974, several clinical and radiologic scoring systems have been developed for this purpose, including Ranson's criteria, the acute physiology and chronic health evaluation (APACHE II) scoring system and the CT severity index (CTSI) and recently, the MCTSI. In some previous studies the authors have reported conflicting results, questioning the validity of above mentioned scores in predicting the prognosis of pancreas. ${ }^{11}$

In our study, we calculated the extra pancreatic necrosis (EPN) volume in the early phase (i.e between 3-6 days of onset of disease) for predicting the prognosis of patients with acute pancreatitis and it is compared with MCTSI. Considering the fact that severe acute pancreatitis can occur in patients within Balthazar groups D and $\mathrm{E}$ without pancreatic necrosis, ${ }^{12}$ we did not include pancreatic necrotic volume along with EPN to prognosticate acute pancreatitis in our study.

\section{Subjects and Methods}

\section{Subjects}

This prospective observational study was approved by the local ethical committee institutional ethics committee. The written-informed consent was obtained from all patients.

All patients (from May 2017 to May 2019) with clinically suspected acute pancreatitis and initial CECT images done between 3-6 days of onset were included in this study.
The patients with definite contraindications for iodine based contrast agents were excluded from this study. A total of 48 patients were included after considering the inclusion and exclusion criteria.

\section{Methodology \\ CT Protocol}

CECT was done in all patients after obtaining serum creatinine levels. CT was performed in a 64 Slice CT (Light speed VCT, GE healthcare). The protocol included a plain and arterial ( 15-30 second) phases for upper abdomen covering from dome of diaphragm to iliac crest level and covering full abdomen from the diaphragmatic dome to ischium in hepatic venous phase ( $60-80$ second). Intravenous contrast agent iopamidol (Lek-Pamidol 370, Unique pharmaceuticals, India) was injected at the rate of $4 \mathrm{ml} / \mathrm{sec}$ using pressure injector.

The imaging parameters were as follows: tube voltage, $120 \mathrm{kV}$; tube current, $200 \mathrm{mAs}$; field of view $42 \mathrm{~cm}$; reconstruction thickness $0.625 \mathrm{~mm}$; and matrix $512 \times 512$.

\section{Image Analysis}

The CT images was analyzed on an AW sever (advanced workstation 2.0, GE systems, Milwaukee, USA). As per the Atlanta classification, Pancreatic necrosis was defined as area of non-enhancement of pancreatic parenchyma after intravenous administration of contrast media. EPN includes peri pancreatic and contiguous retroperitoneal fat necrosis; defined by fat infiltration, collection of fluid/ solid components and with increased attenuation (more than 20-30 HU) with heterogenous appearance. ${ }^{13,14}$ The calculation of EPN volume in hepatic venous phase excludes the pancreatic parenchymal necrosis and ascites. The volume of EPN was expressed in cubic centimeters (cc). Modified CTSI was also calculated for each patient.

Manual or semi-automatic outlining of EPN for every 5-10 sections was done using segmentation tool in AW server 2.0 ( - Figs. $\mathbf{1 A}$ and $\mathbf{B}$ ). Automatic interpolation of the sections in between was done in the same software. After correction of the outline, region of interest (ROI) was converted to volumetric image and volume was calculated using the same software ( - Fig. 1C). If more than one collection were present, the sum of their volumes was taken for study purpose.

\section{Outcome Parameters}

The Outcome parameters were collected from the hospital information system.

The parameters were

1. Duration of hospital stay (in days)

2. Duration of ICU stay (in days)

3. Need for percutaneous intervention (CT guided drainage of pancreatic fluid) or surgical intervention (necrosectomy).

4. Evidence of infection (Elevated WBC count $>11000$ / $\mathrm{mm}^{3}$; or evidence of infection proved with culture and sensitivity testing or gram staining of the specimens or elevated Procalcitonin $>0.5 \mathrm{ng} / \mathrm{ml}$ or serum $\mathrm{C}$ reactive proteins $>3.0 \mathrm{mg} / \mathrm{L}$ ). 

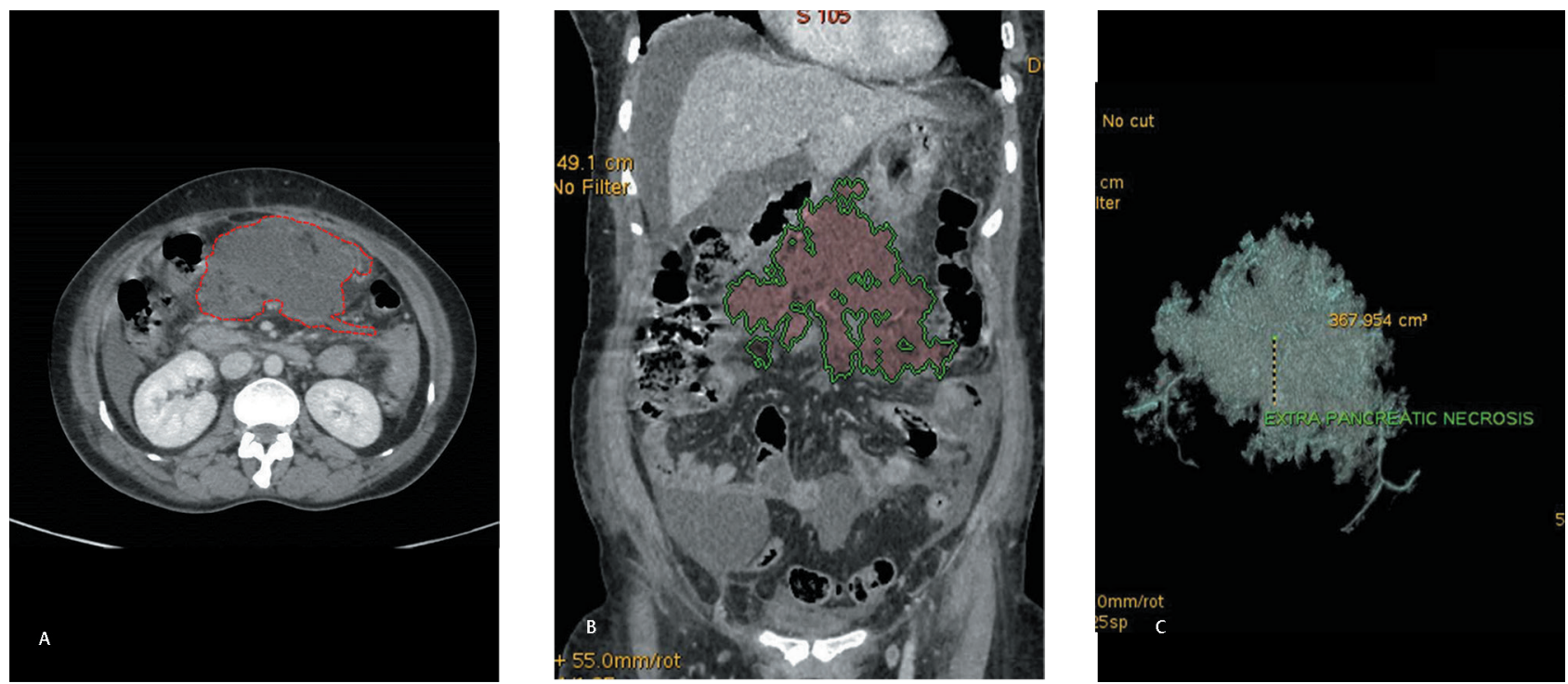

Fig. 1 (A) Axial CECT image of the abdomen shows extrapancreatic necrosis, marked within the red dotted line. (B) Coronal Reformatted CECT image of the abdomen shows area of extra pancreatic necrosis (shaded area with green borders). (C) 3D reconstruction of the extrapancreatic necrosis volume (volume in this patient is $367.9 \mathrm{cc}$ )

\section{Presence of organ failure: ${ }^{5}$}

The following criteria were considered for organ failure; CVS (cardiovascular system-presence of hypotension requiring vasoactive medication.

Renal-Serum creatinine of more than $1.2 \mathrm{mg} / \mathrm{dl}$ or the need for haemodialysis.

Respiratory system - arterial partial pressure of oxygen of less than $60 \mathrm{mmHG}$ or the need for ventilator support.

CNS (central nervous system)- Glasgow Coma scale (GCS) of less than 6

Hematologic system-platelet count of less than or equal to $1 \mathrm{lakh} / \mathrm{ml}$.

Overall organ failure-if any one of the above mentioned organ failure was present the patient falls in to overall organ failure group.

6. Condition at discharge:

Patients were classified into 3 groups according to their general condition at the discharge after the hospital admission.

Group A. Discharge against medical advice and lost to follow up.

Group B. Good-Patients who had a good general condition and stable vitals at the time of discharge.

Group C. Death-patients who died during their course in hospital.

\section{Statistical Tools}

The analysis was done in SPSS version 16.0 for windows. Descriptive analysis such as mean, standard deviation and percentage were used to exhibit the clinical parameters considered in the research pro-forma. Pearson Correlation was used to assess the significant relationship between selected objective variables. All the statistical tests were examined with $5 \%(\mathrm{p} \leq 0.05)$ level of significance.

\section{Results}

51 patients were included in this study, out of which 3 patients had an early discharge within 2 days of admission against medical advice, hence was excluded. Thus 48 patients with acute necrotizing pancreatitis were included in this study.

In our study, Age of the patients ranged from 17 to 65 years (mean age $=43.7$ years), with $83.3 \%$ males and $16.6 \%$ females . $52.9 \%$ of the pancreatitis was secondary to ethanol abuse and $17 \%$ due to gall stones.

\section{EPN Volume versus Outcome Parameters}

The Mean EPN volume was 315.58 cc ( $S D=182.8$; Median = 55.5). Using Pearson's correlation, we found a statistically significant correlation, between the EPN volume and duration of hospital stay, need for percutaneous drainage, necrosectomy, creatinine values, estimated glomerular filtration rate (eGFR), $\mathrm{PaO} 2$ of less than $60 \mathrm{~mm} \mathrm{Hg}$, GCS less than 8, hypotension requiring vasoactive medications, overall organ failure and duration of ICU stay (-Tables $\mathbf{1}$ and $\mathbf{2}$ ).

Presence of hypotension $(r=0.412)$, elevated creatinine levels $(r=0.445)$, reduced eGFR level $(r=0.415)$, duration of hospital stay $(r=0.401)$ and presence of overall organ failure $(r=0.392)$, are the parameters in descending order which showed a statistically significant elevation in their values with the rise of EPN volumes.

Statistically significant correlation could not be found between EPN volume, condition at discharge and occurrence of death.

\section{Serum Amylase Levels versus EPN Volume}

Thirty-five patients had serum amylase levels done within first week of the admission. The levels of serum amylase 
Table 1 Correlation between extra pancreatic necrosis (EPN) volume and outcome parameters

\begin{tabular}{|l|l|l|l|l|l|l|l|}
\hline & & $\begin{array}{l}\text { Duration } \\
\text { of } \\
\text { Hospital } \\
\text { stay }\end{array}$ & $\begin{array}{l}\text { Condition } \\
\text { at } \\
\text { discharge }\end{array}$ & $\begin{array}{l}\text { Intervention } \\
\text {-percutaneous } \\
\text { drainage }\end{array}$ & $\begin{array}{l}\text { Intervention } \\
\text {-necrosectomy }\end{array}$ & $\begin{array}{l}\text { Creatinine } \\
(>1.2 \mathrm{mg} / \mathrm{dL})\end{array}$ & $\begin{array}{l}\text { eGFR } \\
(<60 \mathrm{~mL})\end{array}$ \\
\hline $\begin{array}{l}\text { EPN } \\
\text { Volume }\end{array}$ & $\begin{array}{l}\text { Pearson } \\
\text { correlation }\end{array}$ & $0.401^{\mathrm{a}}$ & 0.19 & $-0.335^{\mathrm{b}}$ & $-0.385^{\mathrm{a}}$ & $0.445^{\mathrm{a}}$ & $0.415^{\mathrm{a}}$ \\
\cline { 2 - 9 } & \begin{tabular}{l} 
p-Value \\
\cline { 2 - 8 }
\end{tabular} & 0.005 & 0.195 & 0.02 & 0.007 & 0.002 & 47 \\
\hline
\end{tabular}

Abbreviations: eGFR, estimated glomerular filtration rate; EPN, extra pancreatic necrosis.

aCorrelation is significant at 0.01 level

${ }^{b}$ Correlation is significant at 0.05 level

Table 2 Correlation between extra pancreatic necrosis (EPN) volume and prediction of organ failure

\begin{tabular}{|c|c|c|c|c|c|c|c|c|}
\hline & & $\begin{array}{l}\mathrm{PaO} 2<60 \mathrm{~mm} \\
\mathrm{Hg}\end{array}$ & $\begin{array}{l}\text { GCS } \\
(<8)\end{array}$ & Hypotension & $\begin{array}{l}\text { Cardiac } \\
\text { failure-echo }\end{array}$ & $\begin{array}{l}\text { Organ } \\
\text { failure } \\
\text { (overall) }\end{array}$ & $\begin{array}{l}\text { Duration of } \\
\text { ICU stay }\end{array}$ & $\begin{array}{l}\text { Occurrence of } \\
\text { Death }\end{array}$ \\
\hline \multirow[t]{3}{*}{$\begin{array}{l}\text { EPN } \\
\text { Volume }\end{array}$} & $\begin{array}{l}\text { Pearson } \\
\text { correlation }\end{array}$ & $0.386^{\mathrm{a}}$ & $0.370^{\mathrm{a}}$ & $0.412^{\mathrm{a}}$ & -0.051 & $0.392^{\mathrm{a}}$ & $0.397^{\mathrm{a}}$ & 0.255 \\
\hline & $p$-Value & 0.007 & 0.01 & 0.004 & 0.896 & 0.006 & 0.006 & 0.094 \\
\hline & $\begin{array}{l}\text { Number of } \\
\text { patients }\end{array}$ & 48 & 48 & 48 & 9 & 48 & 46 & 44 \\
\hline
\end{tabular}

Abbreviations: EPN, extra pancreatic necrosis; GCS, Glasgow Coma Scale.

${ }^{a}$ Correlation is significant at 0.01 level

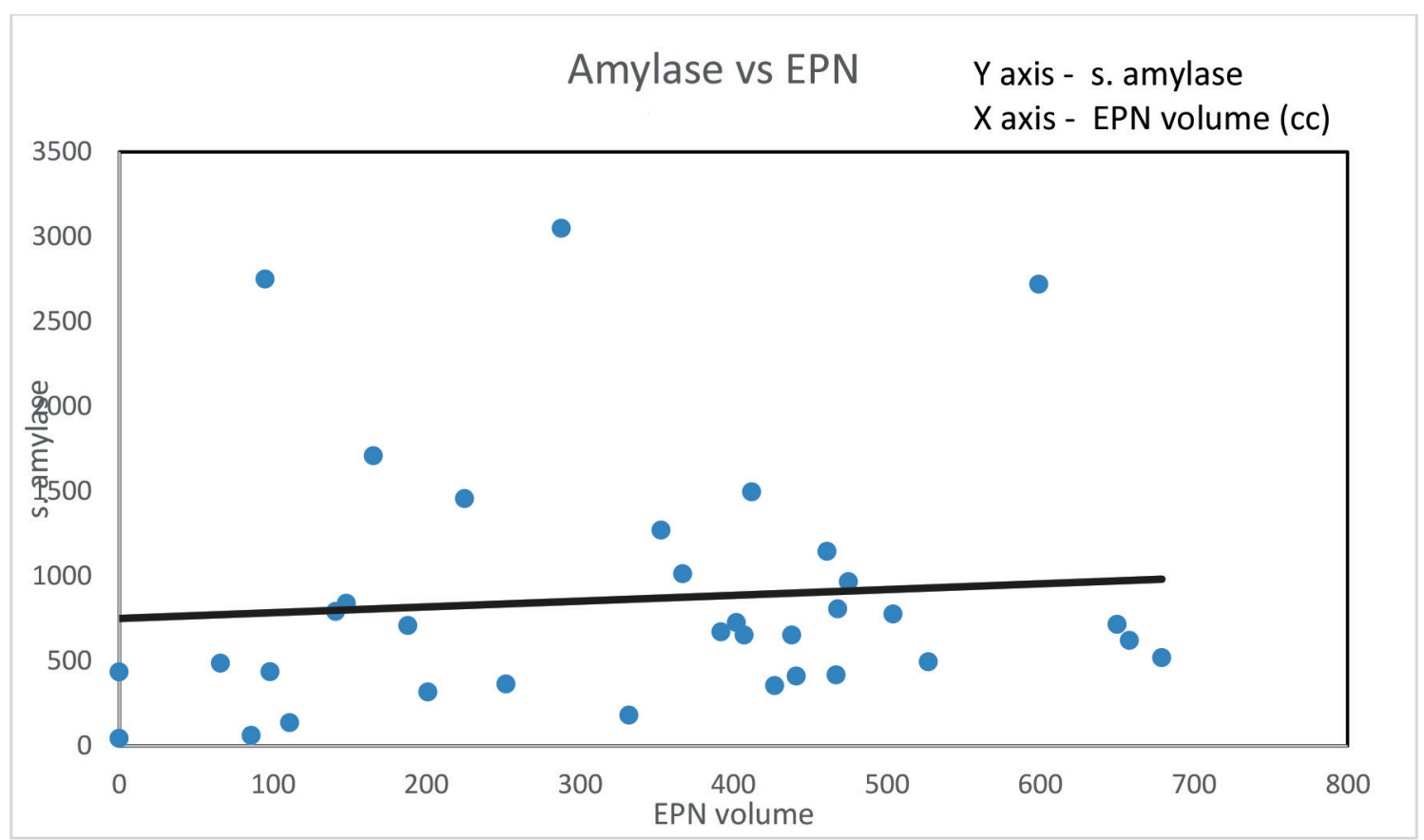

Fig. 2 Amylase versus EPN volume. EPN, extra pancreatic necrosis.

showed a poor positive correlation with the EPN volume (-Fig. 2).

\section{Modified CTSI versus Outcome Parameters}

The correlation between Modified CTSI and outcome parameters were also analyzed using Pearson's correlation. There was no significant correlation between mCTSI and any parameters ( $\mathbf{- T a b l e s} \mathbf{3}$ and $\mathbf{4}$ ).

\section{ROC Curve}

ROC Curve analysis was performed to assess the EPN volume, modified CTSI with overall organ failure. 
Table 3 Correlation between modified CT severity index (CTSI) and outcome parameters

\begin{tabular}{|l|l|l|l|l|l|l|l|}
\hline & & $\begin{array}{l}\text { Duration } \\
\text { of hospital } \\
\text { stay }\end{array}$ & $\begin{array}{l}\text { Condition at } \\
\text { discharge }\end{array}$ & $\begin{array}{l}\text { Intervention } \\
\text {-percutaneous } \\
\text { drainage }\end{array}$ & $\begin{array}{l}\text { Intervention } \\
\text {-necrosectomy }\end{array}$ & $\begin{array}{l}\text { Creatinine } \\
(>1.2 \mathrm{mg} / \mathrm{dL})\end{array}$ & $\begin{array}{l}\text { eGFR } \\
(<60 \mathrm{~mL})\end{array}$ \\
\hline $\begin{array}{l}\text { Modified } \\
\text { CTSI }\end{array}$ & $\begin{array}{l}\text { Pearson } \\
\text { correlation }\end{array}$ & 0.043 & 0.127 & -0.175 & -0.103 & -0.043 & -0.032 \\
\cline { 2 - 8 } & $p$-Value & 0.773 & 0.39 & 0.234 & 0.484 & 0.775 & 0.832 \\
\cline { 2 - 9 } & $\begin{array}{l}\text { Number of } \\
\text { patients }\end{array}$ & 48 & 48 & 48 & 48 & 47 & 47 \\
\hline
\end{tabular}

Abbreviations: CTSI, CT severity index; eGFR, estimated glomerular filtration rate.

Table 4 Correlation between modified CT severity index (CTSI) and prediction of organ failure

\begin{tabular}{|c|c|c|c|c|c|c|c|c|}
\hline & & $\begin{array}{l}\mathrm{PaO} 2 \\
<60 \mathrm{~mm} \mathrm{Hg}\end{array}$ & GCS $(<8)$ & Hypotension & $\begin{array}{l}\text { Cardiac } \\
\text { failure- } \\
\text { echo }\end{array}$ & $\begin{array}{l}\text { Organ failure } \\
\text { (overall) }\end{array}$ & $\begin{array}{l}\text { Duration } \\
\text { of ICU stay }\end{array}$ & $\begin{array}{l}\text { Occurrence of } \\
\text { death }\end{array}$ \\
\hline \multirow[t]{3}{*}{$\begin{array}{l}\text { Modified } \\
\text { CTSI }\end{array}$} & $\begin{array}{l}\text { Pearson } \\
\text { correlation }\end{array}$ & -0.014 & 0.123 & 0.031 & 0.144 & -0.132 & 0.155 & 0.225 \\
\hline & $p$-Value & 0.924 & 0.404 & 0.834 & 0.711 & 0.372 & 0.516 & 0.084 \\
\hline & $\begin{array}{l}\text { Number of } \\
\text { patients }\end{array}$ & 48 & 48 & 48 & 9 & 48 & 46 & 44 \\
\hline
\end{tabular}

Abbreviations: EPN, extra pancreatic necrosis; GCS, Glasgow Coma Scale.

Table 5 AUC for EPN volume in predicting organ failure

\begin{tabular}{|l|l|l|l|l|}
\hline \multicolumn{3}{|c|}{ Area under the curve } \\
\hline Area & Standard error ${ }^{\mathrm{a}}$ & \multirow{2}{*}{$p$-Value $^{\mathrm{b}}$} & \multicolumn{2}{c|}{ Asymptotic 95\% confidence interval } \\
\cline { 3 - 5 } & & & Lower bound & 0.887 \\
\hline 0.737 & 0.077 & 0.005 & 0.587 & Upper bound \\
\hline
\end{tabular}

Abbreviations: AUC, area under curve; EPN, extra pancreatic necrosis.

Under the nonparametric assumption

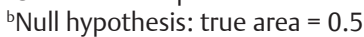

\section{ROC Curve}

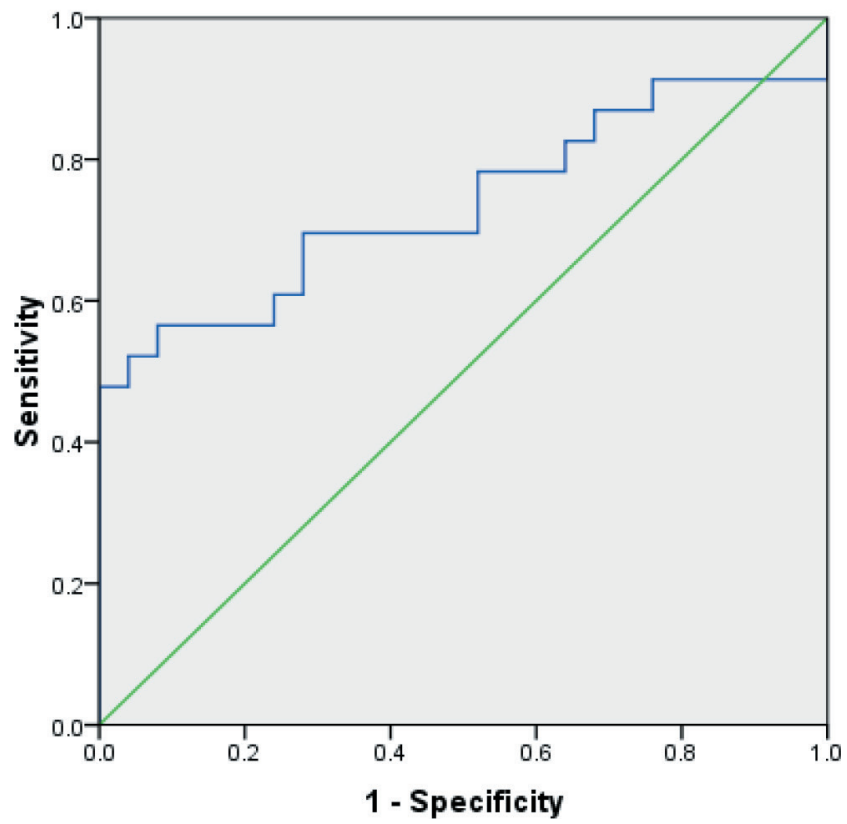

Fig. 3 ROC analysis of extra pancreatic necrosis (EPN) in predictability of organ failure

\section{A. Extra pancreatic necrosis in predicting overall organ failure:}

In this study, out of the 48 patients 23 had one or more organ failures. On the basis of EPN volume, the ROC curves yielded an AUC (-Table 5) of 0.737 (95\% confidence interval [CI]:0.58, 0.88 ) in predicting organ failure and is statistically significant with a $p$-value of 0.005 ( Fig. 3, - Table 5). An EPN volume of 360 cc showed $69.6 \%$ sensitivity, $72 \%$ specificity, positive likelihood ratio of 2.4 and negative likely hood ratio of 0.43 . An EPN volume of 194 cc showed a higher sensitivity of $78 \%$, but with decreased specificity (44\%).

\section{B. Modified CTSI in predicting overall organ failure:}

Modified CTSI yielded an AUC of 0.394 (95\% confidence interval $[\mathrm{CI}]: 0.232,0.556)$ in predicting overall organ failure, which was not statistically significant $(p=0.208)$ ( - Fig. 4). Moreover modified CTSI performed lesser than the EPN volume in predicting overall organ failure (AUC of 0.394 for modified CTSI as compared with 0.737 for EPN).

Correlation between EPN Volume and Modified CTSI Positive correlation $(r=0.282)$ found between modified CTSI and EPN volume was not statistically significant $(p=0.052)$ (-Table 6). 


\section{ROC Curve}

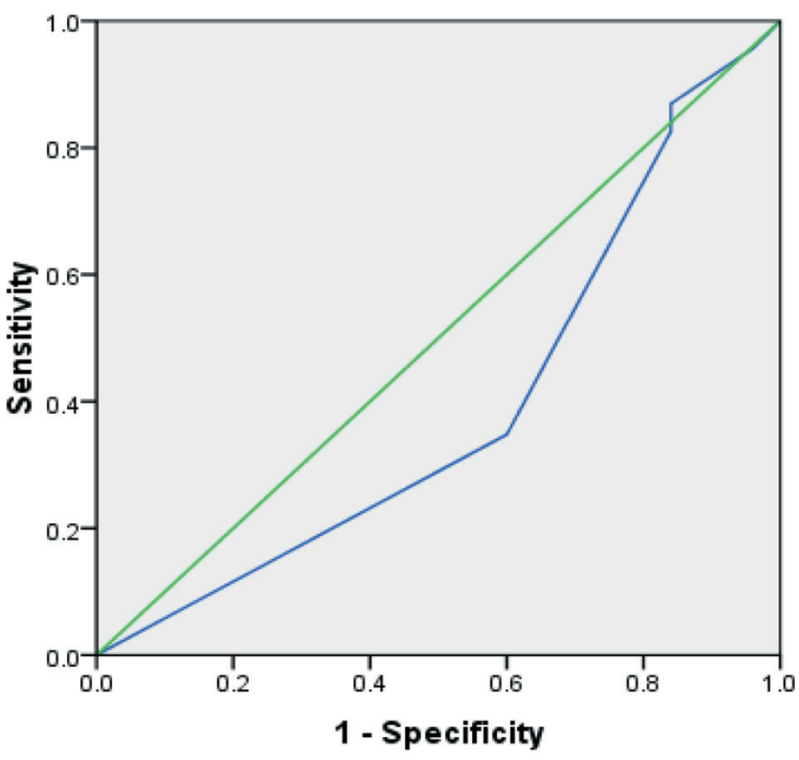

Diagonal segments are produced by ties.

Fig. 4 ROC analysis of modified CT severity index (CTSI) in overall organ failure.

Table 6 Correlations between EPN volume and modified CTSI

\begin{tabular}{|c|c|c|}
\hline & & Modified CTS \\
\hline \multirow[t]{3}{*}{ EPN Volume } & Pearson Correlation & 0.282 \\
\hline & $p$-Value & 0.052 \\
\hline & $N$ & 48 \\
\hline
\end{tabular}

\section{Discussion}

Early evaluation of the severity of acute pancreatitis is essential, to allow the clinician to predict the patient's clinical course, estimate prognosis, and determine the need for admission to the intensive care unit.

An increase in EPN volume showed statistically significant correlations with presence of outcome parameters such as raised creatinine, reduced eGFR, presence of hypotension requiring vasoactive medications, reduction in $\mathrm{PaO} 2$, neurological status of patient, presence of overall organ failures and duration of the hospital \& ICU stay.

Among the outcome parameters, highest correlation of EPN volume was found in patients with hypotension. Elevated serum creatinine, reduced eGFR, duration of hospital stay and presence of overall organ failure also correlated with EPN volume in a descending order of significance. These findings suggest that estimation of EPN volume with CECT, between the 3rd and 6th day of onset of symptoms in acute necrotizing pancreatitis can be used as an early predictor of final outcome of the patient.

We propose a cut off value of $360 \mathrm{cc}$ of EPN volume, beyond which the patient has an increased risk of developing organ failure with a $69.6 \%$ sensitivity, $72 \%$ specificity, positive likelihood ratio of 2.4 and negative likelihood ratio of 0.43 in predicting overall organ failure. In our study when we reduced the cut off to $194 \mathrm{cc}$, though the sensitivity was increased to $78 \%$, the specificity was significantly dropped to $44 \%$. In the study done by Meyrignac et al, they have proposed cut off value of $\sim 100 \mathrm{cc} .{ }^{14}$ The sensitivity and specificity in their study were, respectively, $95 \%$ and $83 \%$ for predicting organ failure. In a similar study, Val et al. set a threshold extrapancreatic necrosis volume of $119.11 \mathrm{~mL} \cdot{ }^{15}$ In another study by Çakar İ et al, EPN volume of $287 \mathrm{cc}$ was used as cut off value for predicting the development of organ failure with a sensitivity of $86 \%$ and a specificity of $74 \%{ }^{16}$ We attribute the higher threshold value in our study to the lower number of patients. Aggressive management can be directed to these patients with high EPN volume even before the signs of florid organ failure set in.

In our study, Serum amylase showed poor positive correlation with the EPN volume, which was not statistically significant $(p=0.60)$. This is to state that follow up of serum amylase cannot be used as a predictor for volume of extra-pancreatic necrosis and indirectly, organ failure. The results were similar to the study done by Subramanian et al. ${ }^{17}$ In their study also, they found no significant correlation between the amylase level and organ failure. There was a significant relationship between the increase in duration of the hospital stay and increased EPN volume in our study. A similar trend was also seen in case of ICU stay.

When compared with modified CTSI, the EPN volume gave a statistically significant and larger Area Under Curve (AUC) for predicting the overall organ failure, suggesting a better performance of EPN volume over Modified CTSI, which was similar to the studies by Meyrignac et al and Çakar İ et al. ${ }^{14,16}$ Besides, EPN volume also has the advantage of being more quantitative than the modified CTSI where the parenchymal necrosis volume is arbitrarily taken as $<30 \%$ or $>30 \%$. Moreover the amount of peripancreatic inflammations whatever may the volume, had a score of 4 (out of 10) in modified CTSI, this may be underestimated or overestimated, and can affect the total score significantly, thus affecting the grading of severity. However these results were applicable only to a subset of acute pancreatitis patients with EPN. MCTSI is not designed to prognosticate only patients with EPN; it is meant to prognosticate all patients with pancreatitis. In our study we did not evaluate the role of modified CTSI in acute pancreatitis patients without extra pancreatic necrosis.

A total of $11(22.9 \%)$ patients underwent percutaneous drainage and $6(12.5 \%)$ patients underwent necrosectomy. The need for surgical interventions (necrosectomy) and percutaneous drainage, showed a statistically significant association with the EPN volume. However both the interventions showed a negative Pearson correlation and an inverse relationship with EPN volume, which can be due to multiple other negative influences (like age, general condition of the patient, site of the collection and its accessibility, financial status etc.) where the patient is not undergoing the procedure even when indicated. Hence the relationship between EPN volume and need for interventions need further studies, by eliminating those negative influences wherever possible. Modified CTSI had no statistically significant correlation with percutaneous interventions in our study. 
Unlike previous study by Meyrignac et $a l,{ }^{14}$ we could not find statistically significant associations between the presence of infection and EPN volume. The condition at discharge also didn't show any correlation with the initial EPN volume, because this can be influenced by several other factors during the course of hospital stay, like age, general condition of the patient, coexistent comorbidities, evolution of the organ failure status, infections and financial status.

Our study had few limitations. The first being small sample size with non-randomized design. Apart from this we did not include the incidence of peripancreatic complications and its relation with the EPN volume in our study. The evolution of EPN volume and its correlation with the evolution of outcome parameters was also not included in this study.

\section{Conclusion}

The volume of EPN calculated between $3^{\text {rd }}$ and $6^{\text {th }}$ day of onset of symptoms, showed a significant correlation with the outcome in patients with acute necrotizing pancreatitis. Though it is time consuming, since it is based on an objective criteria, a threshold value of 360 cc of extra pancreatic necrosis volume, may serve as a good and early imaging predictor for development of organ failure. Aggressive management may be directed toward those patients with increased EPN volume, so as to prevent the occurrence and severity of renal failure, hypotension and prolonged hospital stay.

\section{Conflict of Interest}

None declared.

\section{References}

1 Frossard J-L, Steer ML, Pastor CM. Acute pancreatitis. Lancet 2008;371(9607):143-152

2 Otsuki M, Takeda K, Matsuno S, et al. Criteria for the diagnosis and severity stratification of acute pancreatitis. World J Gastroenterol 2013;19(35):5798-5805
3 Balthazar EJ, Ranson JH, Naidich DP, Megibow AJ, Caccavale $\mathrm{R}$, Cooper MM. Acute pancreatitis: prognostic value of CT. Radiology 1985;156(3):767-772

4 Bollen TL, Singh VK, Maurer R, et al. Comparative evaluation of the modified CT severity index and CT severity index in assessing severity of acute pancreatitis. AJR Am J Roentgenol 2011;197(2):386-392

5 Zhao K, Adam SZ, Keswani RN, Horowitz JM, Miller FH. Acute Pancreatitis: Revised Atlanta Classification and the Role of Cross-Sectional Imaging. AJR Am J Roentgenol 2015;205(1):W32-41

6 Thoeni RF. The revised Atlanta classification of acute pancreatitis: its importance for the radiologist and its effect on treatment. Radiology 2012;262(3):751-764

7 Beger HG, Rau B, Mayer J, Pralle U. Natural course of acute pancreatitis. World J Surg 1997;21(2):130-135

8 Steinberg W, Tenner S. Acute pancreatitis. N Engl J Med 1994;330(17):1198-1210

9 Banks PA. Acute pancreatitis: medical and surgical management. Am J Gastroenterol 1994;89(8Suppl):S78-S85

10 Baron TH, Morgan DE. Acute necrotizing pancreatitis. N Engl J Med 1999;340(18):1412-1417

11 Delrue LJ, De Waele JJ, Duyck PO. Acute pancreatitis: radiologic scores in predicting severity and outcome. Abdom Imaging 2010;35(3):349-361

12 Balthazar EJ. Acute pancreatitis: assessment of severity with clinical and CT evaluation. Radiology 2002;223(3):603-613

13 Shyu JY, Sainani NI, Sahni VA, et al. Necrotizing pancreatitis: diagnosis, imaging, and intervention. Radiographics 2014; 34(5):1218-1239

14 Meyrignac O, Lagarde S, Bournet B, et al. Acute Pancreatitis: Extrapancreatic Necrosis Volume as Early Predictor of Severity. Radiology 2015;276(1):119-128

15 del Val A, Pamies J, Collado JJ, Campos MG, Morales NG, Cordón G. Extrapancreatic necrosis volume as early predictor of severity in acute pancreatitis. Pancreatology 2017;17(5):s8

16 Çakar İ, Keven A, Eseroğlu E, Çubuk SM. Role of extrapancreatic necrosis volume in determining early prognosis in patients with acute pancreatitis. Abdom Radiol (NY) 2020;45(5):1507-1516

17 Subramanian A, Albert V, Mishra B, Sanoria S, Pandey RM. Association Between the Pancreatic Enzyme Level and Organ Failure in Trauma Patients. Trauma Mon 2016;21(2):e20773 